\title{
Análisis del subsector museos y su contribución económica en México
}

\section{Azminda Meybelli Román Nieto ${ }^{a}$}

RESUMEN: El presente artículo analiza el papel de los museos en el sector de la cultura en México y su contribución económica. Para ello, se tomó como base para el análisis de los años 2016 y 2017, los resultados del Sistema Nacional de Cuentas del INEGI, (Año base 2013) y la clasificación del Sistema de Clasificación Industrial de América del Norte SCIAN (2018).

Palabras clave: Sector; economía; crecimiento; cultura; museos.

ABSTRACT: This article presents the role of museums in the culture sector in Mexico and how they contribute to the growth and development of the country. For this, the results of the

\footnotetext{
a Universidad Veracruzana. Museo de Antropología de Xalapa. Observatorio Universitario de Museos del Museo de Antropología de Xalapa (OUM-MAX). Contacto: azroman@uv.mx.
} 
National Account System of INEGI, (Base Year 2013) and the classification of the North American Industrial Classification System SCIAN (2018) are taken as the basis for the analysis.

Keywords: Sector; Economy; Growth; Culture; Museums.

\section{Introducción}

L a dimensión económica de la cultura en México ha quedado relegada, básicamente, al número de infraestructura cultural con la que se cuenta, la procedencia de los financiamientos y el consumo de bienes y servicios. Factores como el ingreso que genera y la aportación que realiza a la economía del país, más aún, el nivel de contribución a la productividad de las personas, al desarrollar sus actividades o a la creación de otras, han se han dejado lado, aunque existan indicadores que den fe de ello. Por ello, es importante destacar que el sector de la cultura tiene un potencial para el crecimiento económico y desarrollo del país. En los últimos años, la dinámica social y cultural han cambiado, por lo que, es importante conocer a detalle al sector de la cultura en México. No basta, únicamente, saber en qué y cuánto se gasta, sino también la forma en cómo y para qué, además de los flujos económicos y culturales que están favoreciendo.

Otro aspecto a tomar en consideración es el consumo de bienes y servicios culturales, puesto que propicia un impacto a nivel individual y social, debido a que es por medio de estos que se adquieren conocimientos y habilidades, al propiciar una mayor capacidad productiva en las personas, estableciendo de esta manera, nuevas dinámicas económicas que a simple vista no son visibles y que permiten la creación de un área de oportunidad económica para el país al fomentar la demanda de recursos y la generación de ingresos y empleos. Una de las actividades que integran el sector de la cultura son las relacionadas con el patrimonio cultural, específicamente los museos. Con base en lo anterior es que el presente artículo plantea indagar el papel de los museos en el sector de la cultura en México y la forma en que contribuyen al crecimiento y desarrollo del país, desde la perspectiva de las instituciones. Para el análisis se toman como base los resultados del Sistema Nacional de Cuentas del INEGI, (Año base 2013).

\section{La cultura y su abordaje conceptual}

Para poder explicar al sector cultural desde la perspectiva económica y con ello, ubicar el papel de los museos en México y su contribución al desarrollo y crecimiento económico, es necesario establecer en este artículo una definición de cultura. 
Observatorios universitarios - Observatorio Universitario de Museos

Si bien el término puede conceptualizarse desde las ciencias sociales y las humanidades, partiendo de la idea de que la cultura es "una producción de sentido", para el caso que nos ocupa utilizaremos las nociones emitidas por los organismos internacionales encargados de establecer las políticas en materia de cultura y el marco legislativo nacional pero, sobre todo, conocer los criterios que permiten la caracterización de las actividades relacionadas con la cultura y, en consecuencia, analizarla; es decir: ¿qué se va a medir? y ¿para qué?

En ese sentido, la UNESCO en su Conferencia Mundial sobre Políticas Culturales, llevada a cabo en la ciudad de México en 1982, refiere a la cultura como el "conjunto de los rasgos distintivos, espirituales y materiales, intelectuales y afectivos que caracterizan a una sociedad o a un grupo social", es decir, que dan identidad y sentido de pertenencia. Sin embargo, específica que la cultura es "además de las bellas artes y las letras, los modos de vida, los derechos fundamentales al ser humano, los sistemas de valores, las tradiciones y las creencias", por lo que las manifestaciones y expresiones de la cultura son resultado de este proceso de creación, producción y trasmisión.

En el ámbito nacional, la noción sobre cultura se ha definido desde el marco legislativo, específicamente, en la Ley General de Cultura y Derechos Culturales, que en su artículo 3ero. Menciona que "Las manifestaciones culturales son los elementos materiales e inmateriales pretéritos ya cuales, inherentes a la historia, arte, tradiciones, prácticas y conocimientos que identifican a grupos, pueblos y comunidades que integran la nación [...]", por ello, para efectos de este análisis, se tomará como referencia, tanto la definición de la UNESCO como la ley de cultura mexicana, en ambas se menciona que la cultura se compone por manifestaciones y expresiones materiales y no materiales que identifican e integran a grupos y comunidades. Parte importante de esas manifestaciones culturales se encuentran albergadas en sitios denominados patrimoniales, específicamente en los museos.

\section{Los museos y su función}

El museo como hoy lo conocemos tuvo diversas transformaciones, desde su concepción en el mundo clásico griego como "receptáculo de colecciones de objetos más o menos sacralizados" (Ballart, 2006: 132), hasta la actualidad, como una institución educativa y de interacción con los bienes culturales. 
El Consejo Internacional de Museos (ICOM, por sus siglas en inglés), ha definido al museo como: "una institución sin fines lucrativos, permanente, al servicio de la sociedad y de su desarrollo, abierta al público, que adquiere, conserva, investiga, comunica y expone el patrimonio material e inmaterial de la humanidad y su medio ambiente con fines de educación, estudio y recreo." Esta definición permite adentrarse en un universo tipológico amplio, por lo que su clasificación permite entender la variedad de sus actividades y funciones; por ello vamos a encontrar recintos por el origen de sus recursos, ubicación o área de influencia; por tipo de colección y temática; así como por el público que asiste.

En cuanto al caso mexicano, se estableció en la política cultural de 1973, a través de la Dirección de Museos (hoy en día Coordinación Nacional de Museos y Exposiciones, dependencia del Instituto Nacional de Antropología e Historia, INAH), que el universo museológico se clasificaría de la siguiente manera:

a) Nacionales: Dan una visión general de la formación histórica y del arte en México, desde los orígenes de la cultura mesoamericana hasta nuestros días.

b) Regionales: Los cuales ofrecen una visión histórica, arqueológica y etnográfica de los aspectos artísticos y culturales de la región, así como su desarrollo histórico y diversidad.

c) Comunitarios: Cuya responsabilidad y jerarquía es propuesta por la comunidad en donde se alberga.

d) De sitio: estos se encuentran ubicados en el contexto natural, establecidos en el área de interés histórico o arqueológico, exhiben los materiales y piezas que pertenecen a este sitio.

Los orígenes de los museos mexicanos datan de 1790 con la inauguración del Gabinete de Historia Natural, posteriormente, entre los siglos XIX al XXI, el número de recintos aumentó. Según la Estadística de Museos del Instituto Nacional de Estadística y Geografía (INEGI), México cuenta con aproximadamente 1156 museos $^{1}$, de los cuales destacan los museos cuyas temáticas principales son historia, arte y arqueología.

\section{La cultura como sector económico y productivo}

¿Pero qué actividades integran el sector de la cultura? Antes de responder a la pregunta es importante definir la razón por la cual la cultura se considera como un sector productivo de

\footnotetext{
${ }^{1}$ Resultados del año 2017.

Recepción: 09/enero/2020

Aceptación: 03/marzo/2020

DOI: En asignación

UVserva 9 abril-septiembre 2020, ISSN: 2448-7430
} 


\section{Observatorios universitarios - Observatorio Universitario de Museos}

la economía. Un sector se caracteriza, principalmente, porque en él intervienen procesos de creación, producción, transmisión y consumo, para el caso de la cultura, además, se integran la apropiación, preservación y formación "materializado en bienes y servicios culturales, caracterizados por su contenido simbólico" (SCNM, 2018). Los sectores de la economía son tres: el primario, caracterizado por la extracción de materia prima; el secundario, basado en la transformación y procesamiento de dicha materia $\mathrm{y}$, finalmente, el sector terciario, complementario a los anteriores, dedicado básicamente a los servicios.

En México, el sector de la cultura se encuentra en el sector terciario y lo integran las industrias culturales y creativas, las artes visuales y escénicas, la promoción y difusión de la lectura y el patrimonio cultural y material, es decir, las llamadas bellas artes, el entretenimiento y el ocio. Por lo que existen diferentes organizaciones como las empresas de artistas independientes de danza y teatro, y los museos y sitios patrimoniales, por mencionar algunos, que se dedican a la producción de bienes y servicios relacionados con los tópicos mencionados, las cuales se integran a diferentes marcos institucionales, de acuerdo con su actividad principal:

El proceso de valoración económico de la cultura toma en cuenta una serie de variables, tales como el valor agregado en todo el proceso productivo cultural, la generación de empleos, el flujo comercial con el resto del mundo y el apoyo directo e indirecto a otros sectores (Arriaga y González, 2016)

Para realizar el análisis del sector, se utilizará el Sistema de Clasificación Industrial para América del Norte ${ }^{2}$, SCIAN (2018), en el cual se define como un sector a "todas las actividades económicas, productivas o no productivas, con fines de lucro o sin fines de lucro"; en ese sentido, está definición, tiene como marco de referencia en que la actividad sea productiva o conlleve un proceso de producción. Este sistema clasifica las actividades relacionadas con la cultural de la siguiente manera:

71 servicios de esparcimiento culturales y deportivos, y otros servicios recreativos

Lo cual se refiere a unidades económicas que se dedican a los servicios de esparcimiento culturales, deportivos y recreativos. Este sector se divide en tres subsectores: 1) Servicios

\footnotetext{
${ }^{2}$ Creado en 1994, en el que se clasificaron las actividades económicas de manera única para América del Norte, en acuerdo trilateral entre Estados Unidos, Canadá y México.
} 
artísticos, culturales y deportivos, y otros servicios; 2) Museos, sitios históricos, zoológicos y similares y 3) Servicios de entretenimiento en instalaciones recreativas y otros servicios. Para efectos de este trabajo es de interés el subsector 2, el cual es integrado por museos, sitios históricos, zoológicos y similares, el cual se refiere como:

El subsector Museos, sitios históricos, zoológicos y similares agrupa unidades económicas que se dedican principalmente a exhibir colecciones de carácter artístico, científico, histórico y en general de valor cultural; a exhibir plantas y animales salvajes vivos; a hacer posible el acceso del público a edificios históricos, zonas arqueológicas y otros lugares de interés histórico, y a hacer posible el acceso del público a zonas naturales y otros sitios del patrimonio cultural de la nación (SCIAN, 2018)

Lo anterior se explica en el siguiente esquema, donde se visualiza la ubicación de los museos dentro del sector de la cultura:

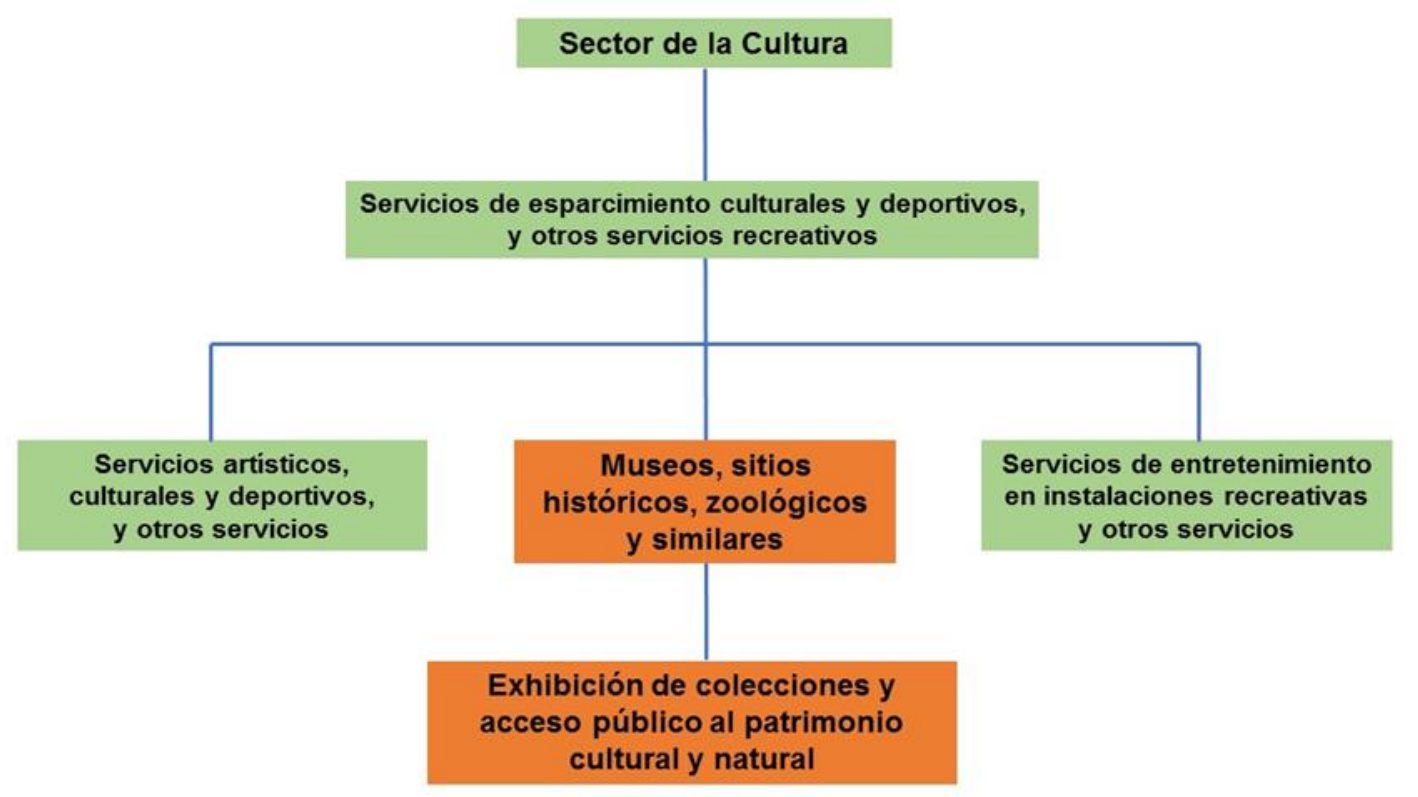

Figura 1. Sector de la Cultura en México. Fuente: Elaboración propia. Con base en el SCIAN, 2018

A continuación, se exponen las actividades económicas que integran el sector de la Cultura a partir de los datos obtenidos en la Cuenta Satélite de la Cultura en México, año base 2013, en dónde se pueden observar actividades que se integran también a otros sectores productivos del país, estas actividades se denominan conexas, puesto que no son exclusivas de la cultura, sino que una parte de estas tienen relación con el ámbito cultural; como ejemplo se ubican las productoras discográficas y grabación de discos compactos, los cuales se integran al sector de Industrias Manufactureras; o Promotores del sector público de espectáculos artísticos, 


\section{Observatorios universitarios - Observatorio Universitario de Museos}

culturales, deportivos con instalaciones para presentarlos, los cuales pertenecen al sector de Servicios Inmobiliarios y de alquiler de bienes tangibles e intangibles.

\section{Tabla1}

Actividades Características del Sector de la Cultura en México

\begin{tabular}{|c|c|}
\hline Clase & Concepto \\
\hline 315224 & Confección en serie de disfraces y trajes típicos \\
\hline 323111 & Impresión de libros, periódicos y revistas \\
\hline 323119 & Impresión de formas continuas y otros impresos \\
\hline 323120 & Industrias conexas a la impresión \\
\hline 325992 & Fabricación de películas, placas y papel fotosensible para \\
\hline 333311 & Fabricación de aparatos fotográficos \\
\hline 334220 & $\begin{array}{l}\text { Fabricación de equipo de transmisión y recepción de señales de radio y televisión, y equipo de } \\
\text { comunicación inalámbrico }\end{array}$ \\
\hline 334310 & Fabricación de equipo de audio y de video \\
\hline 334610 & Fabricación y reproducción de medios magnéticos y ópticos \\
\hline 339911 & Acuñación e impresión de monedas \\
\hline 339930 & Fabricación de Juguetes \\
\hline 339991 & Fabricación y ensamble de instrumentos musicales \\
\hline 511111 & Edición de periódicos \\
\hline 511112 & Edición de periódicos integrada con la impresión \\
\hline 511121 & Edición de revistas y otras publicaciones periódicas \\
\hline 511122 & Edición de revistas y otras publicaciones periódicas integrada con la impresión \\
\hline 511131 & Edición de libros \\
\hline 511132 & Edición de libros integrada con la impresión \\
\hline 511141 & Edición de directorios y de listas de correo \\
\hline 511191 & Edición de otros materiales \\
\hline 511192 & Edición de otros materiales integrada con la impresión \\
\hline 511210 & Edición de software y edición de software integrada con la reproducción \\
\hline 512111 & Producción de películas \\
\hline 512112 & Producción de programas para la televisión \\
\hline 512113 & Producción de videoclips, comerciales y otros materiales audiovisuales \\
\hline 512120 & Distribución de películas y de otros materiales audiovisuales \\
\hline 512130 & $\begin{array}{l}\text { Exhibición de películas y otros materiales audiovisuales (exhibición de películas, videos y otros } \\
\text { materiales audiovisuales }\end{array}$ \\
\hline 512190 & Servicios de postproducción y otros servicios para la industria fílmica y del video \\
\hline 512210 & Productoras discográficas \\
\hline 512220 & Producción de material discográfico integrada con su reproducción y distribución \\
\hline 512230 & Editoras de música \\
\hline 512240 & Grabación de discos compactos (CD) y de video digital (DVD) o casetes musicales \\
\hline 512290 & Otros servicios de grabación del sonido \\
\hline 515110 & $\begin{array}{l}\text { Transmisión de programas de radio (programación musical para ser rentada a centros comerciales y } \\
\text { oficinas) }\end{array}$ \\
\hline 515120 & Transmisión de programas de televisión \\
\hline
\end{tabular}




\begin{tabular}{|c|c|}
\hline 515210 & Producción de programación de canales para sistemas de televisión por cable o satelitales \\
\hline 519110 & Agencias noticiosas \\
\hline 519121 & Bibliotecas y archivos del sector privado \\
\hline 519130 & Edición y difusión de contenido exclusivamente a través de Internet y servicios de búsqueda en la red \\
\hline 519190 & Otros servicios de suministro de información \\
\hline 541310 & Servicios de arquitectura \\
\hline 541320 & Servicios de arquitectura de paisaje y urbanismo \\
\hline 541330 & Servicios de ingeniería \\
\hline 541340 & Servicios de dibujo \\
\hline 541360 & Servicios de levantamiento geofísico \\
\hline 541370 & Servicios de elaboración de mapas \\
\hline 541410 & Diseño y decoración de interiores \\
\hline 541420 & Diseño industrial \\
\hline 541430 & Diseño gráfico \\
\hline 541490 & Diseño de modas y otros diseños especializados \\
\hline 541510 & Servicios de diseño de sistemas de cómputo y servicios relacionados \\
\hline 541721 & $\begin{array}{l}\text { Servicios de investigación científica y desarrollo en ciencias sociales y humanidades, prestados por el } \\
\text { sector privado }\end{array}$ \\
\hline 541810 & Agencias de publicidad \\
\hline 541840 & Agencias de representación de medios \\
\hline 541850 & Agencias de anuncios publicitarios \\
\hline 541920 & Servicios de fotografía y videograbación \\
\hline 541930 & Servicios de traducción e interpretación \\
\hline 611611 & Escuelas de arte del sector privado \\
\hline 611612 & Escuelas de arte del sector público \\
\hline 611631 & Escuelas de idiomas del sector privado \\
\hline 611698 & Otros servicios educativos proporcionados por el sector privado \\
\hline 711111 & Compañías de teatro del sector privado \\
\hline 711121 & Compañías de danza del sector privado \\
\hline 711131 & Cantantes y grupos musicales del sector privado \\
\hline 711191 & Otras compañías y grupos de espectáculos artísticos del sector privado \\
\hline 711211 & Deportistas profesionales \\
\hline 711212 & Equipos deportivos profesionales \\
\hline 711312 & $\begin{array}{l}\text { Promotores del sector público de espectáculos artísticos, culturales, deportivos y similares que cuentan } \\
\text { con instalaciones para presentarlos }\end{array}$ \\
\hline 711320 & $\begin{array}{l}\text { Promotores de espectáculos artísticos, culturales, deportivos y similares que no cuentan con } \\
\text { instalaciones para presentarlos }\end{array}$ \\
\hline 711410 & Agentes y representantes de artistas, deportistas y similares \\
\hline 711510 & Artistas, escritores y técnicos independientes \\
\hline 712111 & Museos del sector privado \\
\hline 712120 & Sitios históricos \\
\hline 712131 & Jardines botánicos y zoológicos del sector privado \\
\hline 712190 & Grutas, parques naturales y otros sitios del patrimonio cultural de la nación \\
\hline 812910 & Servicios de revelado de fotografías \\
\hline 813230 & Asociaciones y organizaciones civiles \\
\hline
\end{tabular}

Fuente: Guía Metodológica para la implementación de las Cuentas Satélite de Cultura en Iberoamérica del Convenio Andrés Bello. Año base 2013. 
Como podemos ver en la tabla anterior, el grupo de actividades que nos ocupa son los museos, pero los museos del sector privado. En este sentido, quedan excluidos los museos del sector público, puesto que, por legislación, y debido a su actividad de exhibición y resguardo, se integran a la categoría de bienes culturales y sitios patrimoniales.

A continuación, se presentan los datos de la aportación del sector de la cultural al Producto Interno Bruto (PIB), de acuerdo con los resultados de la Cuenta Satélite de la Cultura en México, para los años 2016 y 2017, año base 2013:

Tabla 2

Resultados Cuenta Satélite de la Cultura

\begin{tabular}{|l|l|l|}
\hline Concepto & 2016 P & 2017 P \\
\hline Participación económica del sector en el PIB nacional (Porcentaje) & 3.3 & 3.2 \\
\hline PIB del sector de la cultura (Millones de pesos) & 619,558 & 661,505 \\
\hline Producción de mercado (Porcentaje) & 2.5 & 2.4 \\
\hline Gestión pública en actividades culturales (Porcentaje) & 0.2 & 0.2 \\
\hline Asociaciones y organizaciones civiles (Porcentaje) & 0.0 & 0.0 \\
\hline Producción cultural de los hogares (Porcentaje) & 0.6 & 0.6 \\
\hline Puestos de trabajo ocupados & $1,364,134$ & $1,384,161$ \\
\hline
\end{tabular}

Fuente: Sistema de Cuentas Nacionales de México, INEGI

Como observamos en la tabla, la participación económica del sector de la cultura al PIB nacional en 2017 es de 3.2\%, lo cual tuvo un decrecimiento con respecto al año anterior. También destaca el número de puestos de trabajo ocupados, el cual aumentó ese año un aproximado de 20,027 lugares respecto al 2016. Con base en lo anterior, los datos que a continuación se presentan corresponden a la oferta y utilización de bienes y servicios culturales para el año 2017.

Sin embargo, es importante destacar la participación del PIB del sector de la cultura en otros sectores económicos, es decir, con relación a su contribución con la economía en general. 
Tabla 3

Participación del PIB de la Cultura en Sectores de Actividad Económica, 2017

\begin{tabular}{|l|l|l|l|}
\hline Concepto & $\begin{array}{l}\text { Total de } \\
\text { actividades } \\
\text { culturales }\end{array}$ & $\begin{array}{l}\text { Resto de la } \\
\text { economía }\end{array}$ & $\begin{array}{l}\text { Total de la } \\
\text { economía }\end{array}$ \\
\hline 21 Minería & 0.0 & 100.0 & 100.0 \\
\hline 23 Construcción & 0.0 & 100.0 & 100.0 \\
\hline 31-33 Industrias manufactureras & 2.5 & 97.5 & 100.0 \\
\hline 43-46 Comercio & 1.6 & 98.4 & 100.0 \\
\hline 51 Información en medios masivos & 67.6 & 32.4 & 100.0 \\
\hline $\begin{array}{l}\text { 53 Servicios inmobiliarios y de alquiler de } \\
\text { bienes muebles e intangibles }\end{array}$ & 0.3 & 99.7 & 100.0 \\
\hline $\begin{array}{l}\text { 54 Servicios profesionales, científicos y } \\
\text { técnicos }\end{array}$ & 11.4 & 88.6 & 100.0 \\
\hline $\begin{array}{l}\text { 56 Servicios de apoyo a los negocios y } \\
\text { manejo de residuos y desechos, y servicios } \\
\text { de remediación }\end{array}$ & 0.0 & 100.0 & 100.0 \\
\hline 61 Servicios educativos & 1.1 & 98.9 & 100.0 \\
\hline $\begin{array}{l}\text { 71 Servicios de esparcimiento culturales y } \\
\text { deportivos, y otros servicios recreativos }\end{array}$ & 41.9 & 58.1 & 100.0 \\
\hline $\begin{array}{l}\text { 81 Otros servicios excepto actividades } \\
\text { gubernamentales }\end{array}$ & 0.2 & 99.8 & 100.0 \\
\hline $\begin{array}{l}\text { 93 Actividades legislativas, } \\
\text { gubernamentales, de impartición de justicia } \\
\text { y de organismos internacionales y } \\
\text { extraterritoriales }\end{array}$ & 4.8 & 95.2 & 100.0 \\
\hline Otros1/ & 9.3 & 90.7 & 100.0 \\
\hline
\end{tabular}

Fuente: Sistema de Cuentas Nacionales de México, INEGI.

En la tabla anterior destaca que el sector 71 perteneciente a los servicios de esparcimiento culturales y deportivos y otros servicios recreativos, se identifica el 41.9\% de participación con el resto de la economía, lo cual nos permite ir estableciendo que existe una contribución económica fuerte. En ese sentido, veamos a continuación la aportación del PIB de cultura en el mercado, 2017: 
Tabla 4.

PIB del Sector de la Cultura por Mercado y no de Mercado

\begin{tabular}{|l|l|l|l|}
\hline Concepto & $\begin{array}{l}\text { Total (Millones de } \\
\text { pesos a precios } \\
\text { corrientes) }\end{array}$ & $\begin{array}{l}\text { Producción de } \\
\text { mercado } \\
\text { (Porcentaje) }\end{array}$ & $\begin{array}{l}\text { Gestión pública en } \\
\text { actividades culturales } \\
\text { (Porcentaje) }\end{array}$ \\
\hline Artes visuales y plásticas & 7,999 & 93.2 & 6.8 \\
\hline $\begin{array}{l}\text { Artes escénicas y } \\
\text { espectáculos }\end{array}$ & 36,361 & 95.2 & 4.8 \\
\hline Música y conciertos & 7,384 & 82.3 & 17.7 \\
\hline $\begin{array}{l}\text { Libros, impresiones y } \\
\text { prensa }\end{array}$ & 24,613 & 93.2 & 6.8 \\
\hline Medios audiovisuales & 244,807 & 98.7 & 1.3 \\
\hline Artesanías & 123,322 & 99.8 & 0.2 \\
\hline $\begin{array}{l}\text { Diseño y servicios } \\
\text { creativos }\end{array}$ & 54,932 & 98.8 & 1.2 \\
\hline $\begin{array}{l}\text { Patrimonio material y } \\
\text { natural }\end{array}$ & 10,193 & 24.7 & 75.3 \\
\hline $\begin{array}{l}\text { Formación y difusión } \\
\text { cultural en instituciones } \\
\text { educativas }\end{array}$ & 31,017 & 28.6 & NA \\
\hline $\begin{array}{l}\text { Producción cultural de los } \\
\text { hogares }\end{array}$ & 120,876 & NA & \\
\hline
\end{tabular}

Fuente: Sistema de Cuentas Nacionales de México, INEGI.

Como se observa en la tabla 4, la mayor producción la realizan las actividades relacionadas con los medios audiovisuales, sin embargo, para el caso del patrimonio material y natural es en donde mayormente se realizan las actividades relacionadas con la gestión pública, es decir, donde se implementan las políticas en materia de cultura para el cumplimiento de sus logros, objetivos y metas.

Hasta ahora, se han presentado datos correspondientes al sector de la cultura de manera general, lo cual nos permite tener un panorama general de las actividades productivas relacionadas con la cultura y su aportación al PIB nacional. A continuación, se presenta el análisis del subsector museos y su aportación al crecimiento económico de México. 


\section{Subsector museos y su contribución económica}

Los museos, al ser instituciones dedicadas al resguardo, conservación y exhibición del patrimonio cultural del país, adquieren una doble dimensión con relación al sector productivo, puesto que, por un lado, son proveedores de fuentes de empleo y, por el otro, generan un gasto, el cual es realizado por los diferentes públicos que los visitan. Como se mencionó en el apartado anterior, los museos son uno de los tres subsectores que componen el sector de la cultura en México. En ese sentido, también es clasificado por el SCIAN (2018) de la siguiente manera:

\section{Museos}

Unidades económicas dedicadas principalmente a exhibir colecciones de carácter artístico, científico, histórico y, en general, de valor cultural. Incluye también: galerías de arte, museos interactivos, salones de la fama, planetarios, herbarios e insectarios.

\section{Museos del sector privado}

Unidades económicas del sector privado dedicadas principalmente a exhibir colecciones de carácter artístico, científico, histórico y, en general, de valor cultural. Incluye también: galerías de arte, museos interactivos, salones de la fama, planetarios, herbarios e insectarios del sector privado.

\section{Museos del sector público}

Unidades económicas del sector público dedicadas principalmente a exhibir colecciones de carácter artístico, científico, histórico y, en general, de valor cultural. Incluye también: galerías de arte, museos interactivos, salones de la fama, planetarios, herbarios e insectarios del sector público.

En dicha clasificación se hace referencia a los museos del sector público y privado, que, aunque su actividad sustantiva sea la exhibición de colecciones, su marco normativo e institucional es distinto y responden a diferentes intereses. Sin embargo, aunque los museos se encuentren clasificados como un subsector productivo que genera y aporta a la economía de México, los datos obtenidos para analizar su impacto aún no son suficientes para poder realizar comparativos o siquiera evaluar su comportamiento. Los datos obtenidos de la Cuenta Satélite de la Cultura de los años 2016 y 2017, para el rubro específico de museos, son con los que contamos para poder realizar nuestro análisis; sin embargo, como se mencionó anteriormente, aún faltan más datos que permitan realizar un aporte mayor. Al respecto, nuestra aportación es el de visibilizar el área de oportunidad que representa este subsector, si se toma en consideración la dimensión económica de los museos. La información sobre los 


\section{Observatorios universitarios - Observatorio Universitario de Museos}

museos, que se obtuvo de la Cuenta Satélite de la Cultura, se desglosa a continuación. Cabe destacar que el subsector de los museos se encuentra integrado a la categoría de servicios

Tabla. 5

Gasto y financiamiento en museos ${ }^{3}$

\begin{tabular}{|l|l|l|}
\hline \multirow{2}{*}{ Concepto } & 2016 & 2017 \\
\cline { 2 - 3 } & Total & Total \\
\hline Cultura & 778612 & 825867 \\
\hline Bienes y servicios & 586179 & 620796 \\
\hline Bienes y servicios característicos & 391625 & 419898 \\
\hline Bienes & 219840 & 235311 \\
\hline Servicios & 171785 & 184587 \\
\hline Museos & 821 & 853 \\
\hline
\end{tabular}

Fuente: Sistema de Cuentas Nacionales de México, INEGI. Elaboración propia

Como se puede observar en la tabla anterior, el gasto y financiamiento en museos aumentó de 2016 a 2017, en concordancia con el aumento del sector de la cultura, en estos datos se especifican las actividades específicas del ámbito cultural, quedaron fuera las actividades conexas. También se encontraron datos relacionados con el número de puestos de trabajo que tiene tanto el sector cultural como el subsector museos.

Tabla 6.

Puestos totales de trabajo ocupados

\begin{tabular}{|l|l|l|}
\hline \multirow{2}{*}{ Concepto } & 2016 & 2017 \\
\cline { 2 - 3 } & Total & Total \\
\hline Cultura & 1364170 & 1388080 \\
\hline Bienes y servicios & 1009780 & 1029283 \\
\hline Bienes y servicios característicos & 795760 & 814279 \\
\hline Bienes & 457755 & 472155 \\
\hline Servicios & 338005 & 342124 \\
\hline Museos & 2030 & 1907 \\
\hline
\end{tabular}

Fuente: Sistema de Cuentas Nacionales de México, INEGI. Elaboración propia

${ }^{3}$ Estimado en millones de pesos corrientes 
De acuerdo con los datos de la tabla anterior, se observa una disminución de puestos de trabajo totales ocupados entre el 2016 y 2017 para el subsector de los museos. Como lo demuestran los datos obtenidos, aún falta información específica sobre la dimensión económica de los museos en México. Algunos datos que se pueden utilizar para poder realizar un análisis a profundidad que nos permita obtener un mayor panorama y el flujo económico que genera y aporta este subsector son:

1)Número total de visitantes, de los cuales hay que tomar en consideración los que pagan entrada puesto que existen grupos que no realizan un pago, como los menores de edad.

2)El número de museos que tienen costo de entrada y el monto total anual recibido por entrada.

3)La finalidad del costo de entrada, es decir, los rubros a los cuales se desina esa cantidad obtenida por el ingreso al museo.

Los dos primeros puntos se encuentran en la estadística de museos que, año con año, realiza el INEGI; sin embargo, el punto número 3 aún es difícil obtener, puesto que requiere de metodologías específicas para calcularlos y analizarlos.

\section{Conclusiones}

Como ya se mencionó, el papel que tiene el sector de la cultura en el crecimiento y desarrollo de un país no es asunto nuevo. Como se señaló, su contribución puede ser medida a través del Producto Interno Bruto (PIB) y el empleo, además del gasto que genera este sector y los flujos económicos que genera. Sin embargo, para que esta se posicione y potencialice depende de las instituciones que dictaminan dicho orden.

Con base en lo anterior, es posible plantear que el sector de la cultura puede contribuir al crecimiento y desarrollo de un país, siempre y cuando quienes dictaminen las reglas del juego -instituciones políticas-, vean un beneficio particular de acuerdo a sus intereses. Sin embargo, esta postura se puede derrumbar evidenciando y visibilizando que el sector de la cultura genera una actividad económica redituable, en primera instancia, para el individuo, al satisfacer necesidades básicas como vivienda y alimentación; y, en segunda instancia, para la sociedad en general al consumir un bien o servicio, cubriendo otra necesidad: la de entretenimiento. Además, la actual política gubernamental se propuso como meta alcanzar en este rubro el 71, crecer un 4.5\% anual, objetivo que todavía no se cumple. 
Los museos, como se expuso en el texto, ocupan un papel preponderante en el sector de la cultura en México, al ser un subsector que engloba actividades productivas relacionadas con la preservación y formación de bienes culturales, así como el consumo mediante el acceso al patrimonio cultural y natural. Sin embargo, aún se sigue apegando a los lineamientos del Instituto Nacional de Antropología e Historia (INAH) y a la Secretaría de Cultura, que a la fecha siguen vigentes.

Por otro lado, el papel que juegan los museos en la economía del país si bien se destaca, aún no se considera como uno de los principales actores que mueven la dinámica cultural y social del país, sino que su visión se ha encasillado solo a sus funciones sustantivas de resguardo, exhibición, difusión y preservación del patrimonio, y poco se ha buscado fortalecer las actividades específicas: los procesos, las personas y las rutinas. Sin embargo, nos dimos cuenta, con los datos obtenidos en la Cuenta Satélite, que existe una considerable aportación económica que no está siendo aprovechada por las instituciones, debido a que los intereses están puestos en otros sectores económicos del país.

Aunque el actual gobierno federal haya presentado una política cultural en la que garantiza el derecho humano a la cultura y el apoyo a creadores, cineastas, artesanos y artistas; así como a bibliotecas, museos y promoción cultural nacional e internacional, aún no está claro en qué consiste dicho apoyo, al menos no para el asunto que nos ocupa: los museos.

\section{Referencias}

Arriaga Navarrete, R., \& González Pérez, C. (2016). Efectos económicos del sector cultural en México. Análisis Económico, XXXI (77), 219-246.

Cruz Vásquez, E. (2016). Sector cultural. Claves de acceso. México: Ediarte-UANL.

Douglas, N. (2012). Instituciones, cambio institucional y desempeño económico. Cuarta reimpresión, México: Fondo de Cultura Económica.

Heau, C. (2000). "Patrimonio tangible e intangible". En Cárdenas, Eyra (Coord.) 60 años de la ENAH, Memoria, (pp. 82-92), México: CONACULTA-INAH.

Hodgson, G.M. (2011). ¿Qué son las instituciones?, Revista CS, (8), 17-53. https://doi.org/10.18046/recs.i8.1128.

Instituto Nacional de Estadística y Geografía (México) Sistema de Cuentas Nacionales de México: fuentes y metodología: año base 2013/ Instituto Nacional de Estadística y Geografía: México: INEGI, c. (2018). 